Graziele G. Bovi, Oluwafemi J. Caleb, Cornelia Rauh, Pramod V. Mahajan

\title{
Condensation regulation of packaged strawberries under fluctuating storage temperature
}

Journal article | Accepted manuscript (Postprint)

This version is available at https://doi.org/10.14279/depositonce-9722

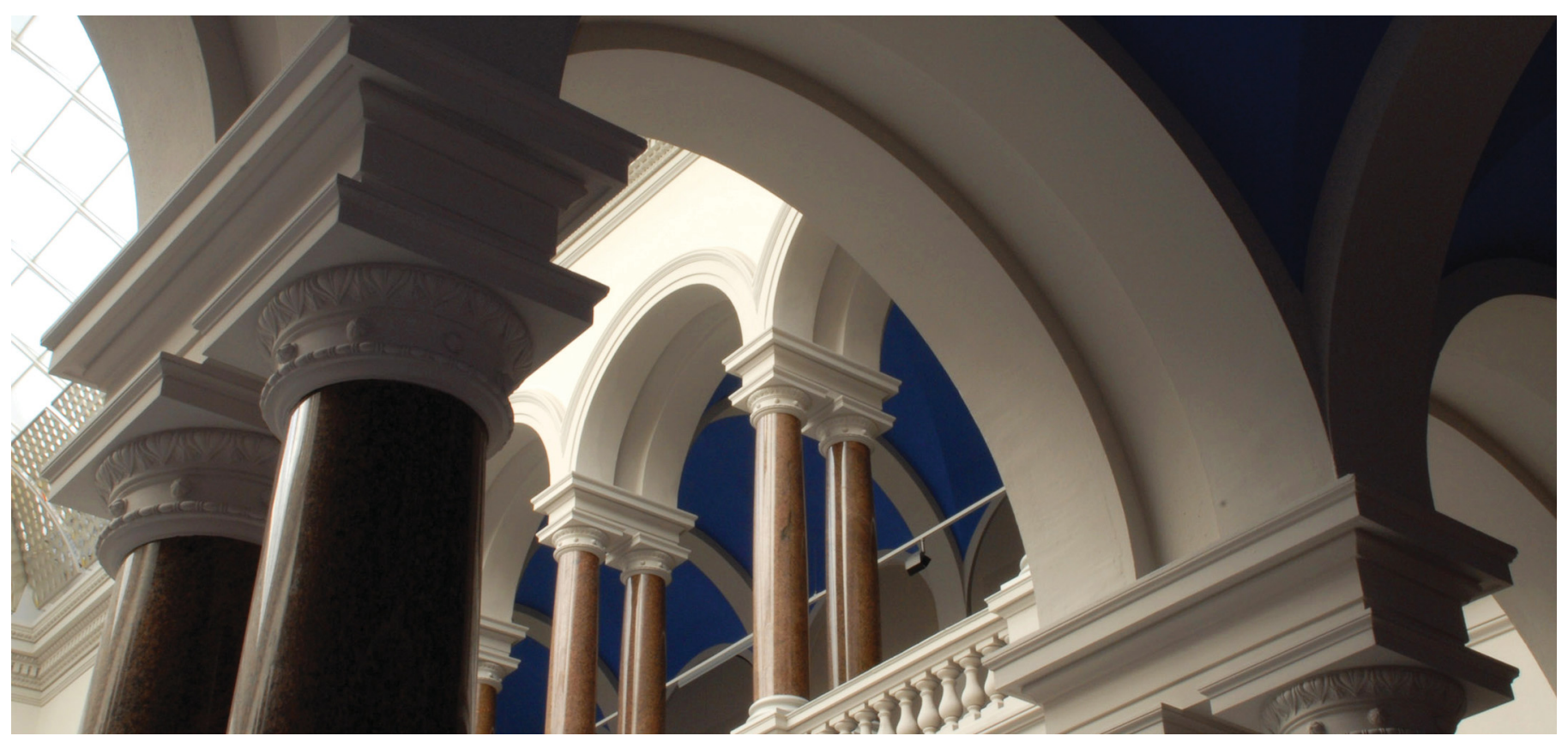

This is the peer reviewed version of the following article:

Bovi, G. G., Caleb, O. J., Rauh, C., \& Mahajan, P. V. (2019). Condensation regulation of packaged strawberries under fluctuating storage temperature. Packaging Technology and Science, 32(11), 545554. https://doi.org/10.1002/pts. 2470

which has been published in final form at https://doi.org/10.1002/pts.2470. This article may be used for non-commercial purposes in accordance with Wiley Terms and Conditions for Use of Self-Archived Versions. 


\section{Condensation regulation of packaged strawberries under fluctuating storage temperature}

In: Packaging Technology \& Science, 1-10

Cite as: Bovi, G.G., Caleb, O.J., Rauh, C., \& Mahajan, P.V. (2019). Condensation regulation of packaged strawberries under fluctuating storage temperature. Packaging Technology and Science; $1-10$.

doi: https://onlinelibrary.wiley.com/doi/full/10.1002/pts.2470 


\title{
Condensation regulation of packaged strawberries under fluctuating storage temperature
}

\author{
Graziele G. Bovi $^{\text {a, b, }}{ }^{*}$, Oluwafemi J. Caleb ${ }^{\text {a, c }}$, Cornelia Rauh ${ }^{\text {b }}$, Pramod V. Mahajan ${ }^{\text {a }}$ \\ ${ }^{a}$ Department of Horticultural Engineering, Leibniz Institute for Agricultural Engineering and \\ Bioeconomy (ATB), Potsdam, Germany \\ ${ }^{\mathrm{b}}$ Department of Food Biotechnology and Food Process Engineering, Technical University of \\ Berlin, Germany \\ ${ }^{\mathrm{c}}$ Post-Harvest and Agro-Processing Technologies (PHATs), Agricultural Research Council \\ (ARC) Infruitec-Nietvoorbij, Stellenbosch 7599, South Africa \\ *Corresponding author: Phone: +49(0)3315699628; E-mail: gbovi@atb-potsdam.de \\ (Graziele G. Bovi)
}

\begin{abstract}
Disruption in cold chain during distribution and retail could have a significant impact on inpackage condensation of optimally designed packaged fresh produce. The aim of this work was to regulate in-package condensation and evaluate the performance of different packaging design systems for strawberries under fluctuating temperatures (between $10{ }^{\circ} \mathrm{C}$ and $20{ }^{\circ} \mathrm{C}$ ) for 5 days. The design included the use of condensation control strategies, namely enhanced permeable films (NatureFlex ${ }^{\mathrm{TM}}$ and Xtend ${ }^{\circledR}$ ) and FruitPad of different fructose content $(0,20$, 30, 35, and $40 \%$ ). Package performance was evaluated in terms of headspace gas composition, mass loss, condensation, physico-chemical changes and visual and ortho-nasal quality evaluation. Percentage mass loss of packaged strawberries ranged from $0.6 \%$ to $4 \%$ and was $33 \%$ for unpackaged. Results also showed that compared to the control sample both strategies (enhanced permeable films and FruitPads) were effective in reducing condensation. In addition, transpirational water loss, results of the water absorbed by the FruitPads and transferred through the films were used to understand the packaging design needs under fluctuating temperature.
\end{abstract}

Keywords: packaging, strawberry, condensation, quality, moisture regulation 


\section{Introduction}

According to Food and Agricultural Organization (FAO), fresh produce have the highest wastage rates $(45 \%)$ of any food product as almost half of all fresh produce produced are wasted [1]. These high wastage rates are due to the fact that fresh produce are unique among food products as they remain metabolically active (e.g. respiring and transpiring) and their shelf and storage life are shortened as consequence of these physiological processes. Nevertheless, improved packaging (e.g. modified atmosphere packaging, MAP) can slow down such processes and consequently prolong product shelf life from growers to consumers by protecting and maintaining quality of product [2]. The beneficial effects of application of MAP technology on fresh produce as well as the ideal modified atmosphere (MA) conditions for a wide variety of fresh produce have been reviewed in numerous studies [3-5]. Even though the benefits of MAP technology are known this technology is still not yet fully applied in practice. This was confirmed by analysing packaged strawberries sold in two different supermarkets in the Potsdam area, Brandenburg, Germany (Table 1) [6].

Nonetheless, over the last 5 years great attention has been given to condensation regulation in MAP for a wide variety of fresh and fresh-cut produce. This is due to fact that the most commonly used material for MAP, polypropylene (PP), has a high gas and water barrier property, and as a result, the low water vapour transmission rate (WVTR) of the lid film causes high humidity in the package headspace. This creates an ideal environment for the mold growth and decay of packaged fresh produce. Studies addressing condensation regulation have been carried out such as by the use of salt trays [7-9], humidity windows with enhanced permeable films [10-15], fructose pads [16], and water absorbers [17, 18]. These strategies have been experimentally tested for different products including strawberry $[8,10$, 16], avocado [17], pomegranate arils [13], mushroom [7], fresh-cut cauliflower [12], tomato $[8,15]$, and fresh-cut iceberg lettuce [11]. Moreover, from Table 1 it is possible to see that at supermarket display points the use of ventilated packages (e.g. use of macro perforations) are being used to help control condensation and heat flow.

The increased interest in condensation regulation is due to the fact that improper condensation control could result in very high or low humidity inside the package, which leads to decrease in product quality and reduced shelf life. In the case of high humidity there is a risk of in-package condensation, leading to promotion of spoilage microorganism growth, while, in the case of lower humidities excessive mass loss, leading to defects in external appearance, such as wilting and shrivelling [19]. Thus, it is clear that condensation regulation is extremely important to further extend shelf-life of fresh produce and it plays an 
important role in reducing food waste and food loss. This has led to a paradigm shift from research focusing on MAP to integrated MAHP systems (Table 2).

Moreover, a wide range of condensation control strategies have been tested for fresh produce packed under MAP and modified atmosphere and humidity packaging (MAHP) conditions at constant temperature $[10,12,13,16]$. However, few studies have been carried out under fluctuating temperature [20]. Hence, the hypothesis of this study is that minor temperature fluctuation during the supply chain can lead to water condensation and optimal package design can effectively regulate in-package humidity under such fluctuations. In this context, the aim of this work was to regulate condensation and evaluate the performance of different packaging design under fluctuating retail market temperatures for 5 days on the quality attributes of strawberries. The design included the use of condensation control strategies, namely enhanced permeable films (NatureFlex ${ }^{\mathrm{TM}}$ and $\mathrm{Xtend}^{\circledR}$ ) and FruitPad of different fructose content $(0,20,30,35$, and $40 \%)$.

\section{Materials and methods}

\subsection{Plant materials}

Fresh strawberries (cv. Flair) were obtained from a commercial grower's fresh market (Karls, Erlebnis-dorf, Elstal, Germany). The strawberries were harvested in the evening and sold within $24 \mathrm{~h}$ the next day, and the average display temperature at the time of purchase was 15 $\pm 3{ }^{\circ} \mathrm{C}$. The strawberries were transported to the Freshness Laboratory, Department of Horticultural Engineering, Leibniz Institute for Agricultural Engineering and Bioeconomy, Potsdam, Germany, under cool conditions. The strawberries were carefully sorted and the damaged, overripe, and poor quality fruit were discarded in order to obtain uniform samples. The strawberries were pre-cooled at temperature of $4{ }^{\circ} \mathrm{C}$ for $2 \mathrm{~h}$ prior to starting the experiments.

\subsection{Transpirational water loss}

It is known that in-package headspace plays an important role in mass loss of packaged strawberries and, therefore, a model based on the degree of filling (DOF) is suitable to address this issue. In this context, the water vapour flux due to transpiration of packaged strawberries was calculated using the model developed by Bovi, Rux [21]. The proposed model (Eq. 1) based on percentage DOF (Eq. 2) was therefore used to calculate the transpiration rate (TR) of packaged strawberries at constant temperature of $12{ }^{\circ} \mathrm{C}$.

$$
T R\left(g \mathrm{~kg}^{-1} h^{-1}\right)=-0.0009 \mathrm{DOF}+0.0398
$$




$$
\operatorname{DOF}(\%)=\frac{V_{\text {product }}}{V_{\text {package }}} \times 100
$$

Where TR is the amount of water lost per $\mathrm{kg}$ of product and per hour, $V_{\text {product }}$ is the product's volume and equals to $250 \mathrm{~mL}$ (strawberry density was considered to be $1 \mathrm{~g} \mathrm{~mL}^{-1}$ ) and $V_{\text {package }}$ is the package's volume and equals to $1020 \mathrm{~mL}$.

Moreover, TR measurements were carried out in packaged strawberries under fluctuating temperature (as described in section 2.4). For this investigation a fixed amount of strawberries $(250 \pm 2 \mathrm{~g})$ were placed in polypropylene (PP) packaging tray $(17 \times 12 \times 5 \mathrm{~cm})$, with corresponding percentage DOF of approximately $25 \%$. The trays were manually filled with strawberries and hermetically sealed (using double sided hermetic tapes) with bi-axially oriented polypropylene (BOPP) Propafilm ${ }^{\mathrm{TM}}$ (Innovia Films, Cumbria, UK). The lidding film on the trays was perforated with 6 micro-perforations of diameter $0.82 \mathrm{~mm}$. These perforations were made in order to maintain the package atmosphere close to air and reduce condensation. The TR was calculated by a gravimetric approach according to Eq. 3:

$$
T R=\frac{m_{i}-m_{t}}{t \cdot\left(\frac{m_{i}}{1000}\right)}
$$

where $T R$ is the transpiration rate $\left(\mathrm{g} \mathrm{kg}^{-1} \mathrm{~h}^{-1}\right), m_{i}$ is the initial mass of the product $(\mathrm{g}) ; m_{t}$ is product mass $(\mathrm{g})$ at a determined time $(\mathrm{t})$ in hours $(\mathrm{h})$. A total of three repetitions were carried out and the mass loss was measured after 5 days using an electronic balance CPA10035 (Sartorius, Göttingen, Germany).

\subsection{Modified atmosphere and humidity packaging design}

FruitPads incorporated with varying fructose content (as active absorbing component) were used to evaluate package performance under the fluctuating temperature. The structure of the Fruitpads (McAirLaid's Vliesstoffe GmbH, Steinfurt, Germany) is as described in Bovi, Caleb [16]. Package types were named according to the percentage of fructose contained were FP-00, FP-20, FP-30, FP-35, and FP-40 for FruitPad containing 0, 20, 30, 35, and $40 \%$ of fructose, respectively. For comparison purpose, other packaging materials with relatively high WVTR such as Xtend® film (StePac, Tefen, Israel) and cellulose-based biodegradable NatureFlex $^{\mathrm{TM}}$ film (Innovia Films, Cumbria, UK) were used (Table 3). The control package and the packages containing FruitPads were covered with BOPP film. Additionally, unpacked strawberries were also analysed to depict the conditions in local Farmers' Market. All lidding films were perforated with 6 micro-perforations of diameter $0.82 \mathrm{~mm}$ (preoptimized design, based on preliminary studies). All packaging trials were performed with PP 
trays $(17 \times 12 \times 5 \mathrm{~cm})$ and strawberries of $250 \pm 5 \mathrm{~g}$. Three replicates of each sample were performed making it a total of 27 packages.

\subsection{Package performance under fluctuating temperature}

All packages were stored for 5 days under fluctuating temperature. The temperature fluctuation profile applied was to mimic the postharvest chain and included precooling, distribution, supermarket and consumer step and was adapted from Matar, Gaucel [22]. Strawberries were packaged in MAHP at $10^{\circ} \mathrm{C}$ and remained at this temperature for $2 \mathrm{~d}$. This step mimicked distribution from field to supermarket. Packages were considered to be at the supermarket for $1 \mathrm{~d}, 12 \mathrm{~h}$ at $20{ }^{\circ} \mathrm{C}$ (supermarket shelves) and for $12 \mathrm{~h}$ at $10{ }^{\circ} \mathrm{C}$ (in supermarket refrigerator). After that packages were considered to be bought and consumers kept it outside the refrigerator for $2 \mathrm{~d}$ at $20{ }^{\circ} \mathrm{C}$. Following quality parameters were assessed at regular intervals.

\subsubsection{In-package relative humidity and headspace gas composition}

Headspace gas composition $\left(\mathrm{O}_{2}\right.$ and $\left.\mathrm{CO}_{2}, \mathrm{kPa}\right)$ inside each package was monitored daily by using a CheckMate 3 gas analyser (PBI Dansensor, Ringsted, Denmark), with an accuracy of $\pm 0.01 \%$ for $\mathrm{O}_{2}$ in the range of $0-1 \%$ and of $\pm 1 \%$ for $\mathrm{O}_{2}>1 \%$ and \pm 0.05 for $\mathrm{CO}_{2}$. Air humidity sensor FHA646R (Ahlborn, Holzkirchen, Germany) was used to monitor air temperature and $\mathrm{RH}$ with an accuracy of $\pm 0.1{ }^{\circ} \mathrm{C}$ and $\pm 2 \%$ in the range $<90 \% \mathrm{RH}$ at nominal temperature $\left(25^{\circ} \mathrm{C} \pm 3{ }^{\circ} \mathrm{C}\right)$, respectively.

\subsubsection{Mass loss and condensation}

Condensation and total strawberry mass loss, was quantified at the end of storage on day 5. The amount of water vapour condensed in the film $(\mathrm{g}$ ) was quantified by weighing the films before and after the removal of condensed water on the lidding films. The water loss through the film, due to permeability, was also calculated from the difference between initial and final weight of the complete package according to Rux et al. [3, 4]. Moreover, the experimental values of water absorbed by pad and water loss over film (Fig. 4), under fluctuating temperature, were used to calculate the water vapor flux due through the film and water flux of FruitPad absorption (Fig. 1). The water vapour flux of both condensation control strategies were calculated dividing total mass of water absorbed/transferred by 120 , which is the number of hours under which the fluctuating temperature experiment ran.

\subsubsection{Physico-chemical changes}

Strawberries were squeezed and juice was extracted. The strawberry juice was then used to measure total soluble solids (TSS), $\mathrm{pH}$ and titratable acidity (TA). A digital refractometer 
(DR301-95, Krüss Optronic, Hamburg, Germany) was used to measure TSS and expressed as $\%$. The TA concentration of the juice sample was measured potentiometrically by titration with $0.1 \mathrm{~mol} \mathrm{~L}^{-1} \mathrm{NaOH}$, to an endpoint of $\mathrm{pH} 7.0$ using an automated T50 M Titrator with Rondo 20 sample changer (Mettler Toledo, Switzerland). The TA concentration was expressed as $\mathrm{g} \mathrm{L}^{-1}$ of citric acid based on fresh mass. The $\mathrm{pH}$ was measured with a $\mathrm{pH}$ meter (inoLab pH720, WTW Series, Weilheim, Germany) after calibrating with pH buffers 4 and 7. Measurements were done in triplicate on days 0,3 and 5.

\subsubsection{Visual and ortho-nasal quality evaluation}

Seven untrained panelists, who are regular consumers and familiar with the quality attributes of strawberry carried out visual and ortho-nasal quality evaluation. Strawberry quality attributes such as texture, appearance, brilliance, odour, and decay were evaluated on a scale of 1 to 5 . In addition, visual observation of in-package condensation on the lidding film was also scored on a scale of 1 to 5. The quality scores (1-5) were adapted from Bovi, Caleb [10] as represented in Table 4.

\subsection{Statistical analysis}

The statistical analysis was carried out using Statistica software (version 10.0, StatSoft Inc., Tulsa, USA) and data obtained was subjected to one-way analysis of variance (ANOVA) and Tukey's test was used to test statistically significant difference set at $p \leq 0.05$. All the results were presented as the mean $(n=3) \pm$ standard deviation (SD).

\section{Results and discussions}

\subsection{Water vapour flux of product and package}

The water vapour flux range due to transpiration of packaged strawberries was $0.0042-0.0047$ $\mathrm{g} \mathrm{h}^{-1}$ at $12{ }^{\circ} \mathrm{C}$ whereas the experimental was $0.0080-0.0088 \mathrm{~g} \mathrm{~h}^{-1}$ at fluctuating temperature, both having the DOF percentage of $25.51 \%$ (Fig 1). The differences in the water flux can be attributed to the fluctuating temperature. These results thus emphasize that fluctuating temperature affect the TR of packaged strawberries as well as the RH as indicated in Fig 2. To a great extent fluctuating temperature should be avoided along the supply chain. In theory in order to avoid condensation inside the package, the flux of water vapour through the package, as well as the FruitPad absorption water flux, should be as close as possible to the rate of transpirational losses of packaged strawberries. As shown in Fig 1 only the control package fulfills this condition. However, as seen from Fig 4 these packages were not able to avoid condensation. This could be due to higher initial transpiration than in the final days of storage and therefore the permeability of the films, as well as the perforations, are not enough to deal 
with the initial water flux and leads to condensation. For that reason it is necessary that the packaging systems should either allow the excess water to exit the package (water prevention) or to be absorbed by the pads (water elimination) in order to avoid the formation of condensation. Therefore, in reality it is needed that not only the flux of packaging system matches the transpiration losses of the produce, but that condensation control strategy is added to the packaging design.

\subsection{In-package relative humidity and gas composition}

Temperature fluctuation had a significant impact on the in-package RH (Fig 2) and in the process of deliquescence. Deliquescence is a phase transition from solid to solution, induced by water uptake from the atmosphere, which in turn is triggered when the in-package $\mathrm{RH}$ is above the deliquescence point $\left(\mathrm{RH}_{\mathrm{o}}\right)$ [23]. $\mathrm{RH}_{\mathrm{o}}$ is the $\mathrm{RH}$ at which crystalline materials, such as fructose, begin absorbing large quantities of water from the atmosphere. Below that point, the process of slow water adsorption takes place. In turn, it is known that $\mathrm{RH}_{\mathrm{o}}$ is an important temperature dependent stability parameter [23]. For example, at $20{ }^{\circ} \mathrm{C}_{\mathrm{RH}}$ for fructose is $64.8 \%$ whereas for 25 and $30{ }^{\circ} \mathrm{C}$ it is of 63.4 and $61.7 \%$, respectively [24]. In the present study, as soon as the packages were closed, the headspace RH was above the deliquescence point of fructose as a result of the transpiration process of strawberry. High headspace RH was observed in all packages until day 3. However, the packages containing FruitPads with higher fructose content (FP-35 and FP-40) showed unexpected rapid decrease of RH when temperature was increased to $20{ }^{\circ} \mathrm{C}$ on day 3 . At this point, the water from the headspace began to be absorbed by the FruitPads at a much faster rate as compared to other packages. This was evident from Fig 4 which showed significant amount of water absorbed by FP-35 and FP-40. Overall, the amount of water absorbed was directly related to the amount of fructose added in FruitPads. Higher the fructose content the higher was amount of water absorbed by the deliquescence process. Therefore, it is important to consider this relation for optimizing fructose content in FruitPads that will maintain RH in the range of 90 to $95 \%$, which is ideally recommended for packaging and storage of fruit and vegetables. In addition, the impact of raising the temperature from 10 to $20{ }^{\circ} \mathrm{C}$ on the last two days of experiment affected the RH of FP-35 and FP-40 packages compared to other packages. Moreover, as shown in Fig 2 the increase in temperature led to an immediate decrease in the RH. The reason for that is that at higher temperatures air can hold more water vapour and as a consequence RH is decreased [25]. After day 1 there already seemed to be a trend to equilibrium, nevertheless, after the temperature fluctuation (from day 2) the equilibrium was affected. 
After 5 days of storage, under fluctuating temperature, the in-package gas composition of different packages varied between $13-19 \mathrm{kPa}$ for $\mathrm{O}_{2}$ and 2-8 $\mathrm{kPa}$ for $\mathrm{CO}_{2}$ (Fig 3). Packages covered with NatureFlex ${ }^{\mathrm{TM}}$ films had the lowest $\mathrm{CO}_{2}(2.15 \mathrm{kPa})$ and highest $\mathrm{O}_{2}(18.8 \mathrm{kPa})$. The marginal atmosphere modification in the NatureFlex ${ }^{\mathrm{TM}}$ films can be attributed to differences in $\mathrm{RH}$ throughout storage (as a consequence of the temperature fluctuation and product transpiration losses). Rosenkranz [15] reported that the oxygen transmission rate (OTR) of NatureFlex ${ }^{\mathrm{TM}}$ films increased 24 times with increasing RH from $56 \% \mathrm{RH}(6.1 \mathrm{~mL}$ $\left.\mathrm{m}^{-2} \mathrm{~d}^{-1}\right)$ to $100 \% \mathrm{RH}\left(148 \mathrm{~mL} \mathrm{~m}^{-2} \mathrm{~d}^{-1}\right)$ at constant temperature of $20{ }^{\circ} \mathrm{C}$. Thus, temperature fluctuation led to changes in RH and directly affected the permeability of the film, which in turn influenced the headspace gas composition as $\mathrm{O}_{2}$ from the environment permeated into the packages covered with NatureFlex ${ }^{\mathrm{TM}}$ film. Moreover, none of the packages had a declined of $\mathrm{O}_{2}$ below $13 \%$ indicating that anaerobic respiration did not take place. All packaging systems used in this study were efficient in preventing anoxic conditions for packaged strawberries. The temperature fluctuation affected the $\mathrm{CO}_{2}$ production to higher extend as compared to $\mathrm{O}_{2}$ consumption.

\subsection{Mass loss and condensation}

Strawberry total mass loss was significantly influenced by type of condensation control strategy used (Fig 4). Highest strawberry mass loss was observed in packages covered with NatureFlex ${ }^{\mathrm{TM}}$ film $(3.68 \%)$ and lowest at the control $(0.61 \%)$. On the other hand, control had the highest in-package water condensation $(\approx 0.19 \mathrm{~g})$, whereas all other packages had 10 times less in-package condensation $(<0.02 \mathrm{~g})$. Tukey's test showed that there was no significant difference in mass loss between the control, Xtend ${ }^{\circ}$, FP-00, FP-20, and FP-30, sample, whereas significant difference in mass loss was observed in packages covered with NatureFlex ${ }^{\text {TM }}$ film $(p \leq 0.05)$. This outcome confirms the high WVTR of NatureFlex ${ }^{\text {TM }}$ film and the need for integrated product-specific package design (Fig 4) (e.g. use of humidity windows). Moreover, mass loss for the unpacked sample was $33.15 \mathrm{~g}(33.16 \pm 0.33 \%)$, this amount is significantly above the recommended maximum acceptable percentage mass loss for strawberries of $6 \%$ [26]. This once more emphasizes the role MAP plays in minimizing mass loss of strawberries.

In addition, results showed that the fluctuating temperature led to a higher mass loss when compared with experiments carried out at $12{ }^{\circ} \mathrm{C}$ for the same 5 days [16]. Under constant temperature, with 2 micro-perforation of $0.7 \mathrm{~mm}$ diameter, the percentage mass loss of strawberries was $0.92,0.62,0.26$ and $0.21 \%$, which represents an increase of 1.4, 1.7, 2.7, and 2.9 times higher for FP-30, FP-20, FP-00, and control, respectively. Nevertheless, not all 
of this increase can be attributed to temperature fluctuation as in this study there were 6 micro-perforations of diameter $0.82 \mathrm{~mm}$, therefore, part of the water released by the product probably escaped through the optimized micro-perforations.

\subsection{Physico-chemical changes}

The range of total acidity (TA), $\mathrm{pH}$, and total soluble solids (TSS), obtained in this study was 8.5-12.0 $\mathrm{g} \mathrm{L}^{-1}$ for citric acid, 3.6-3.8, and 8.7-12.4\%, respectively (Table 5). In this study changes in citric acid were within the range of 7.3-15.8 $\mathrm{g} \mathrm{L}^{-1}$ for six different varieties of strawberries as reported by Kallio, Hakala [27], for cvs. 'Senga Sengana', 'Jonsok', 'Korona', 'Polka', 'Honeoye' and 'Bounty'. The authors evaluated six strawberry varieties in terms of their acid composition. Also, there were no significant difference $(p>0.05)$ within the storage days for control, Xtend, NatureFlex, FP-00, FP-20, FP-30, FP-35 and FP-40 (Table 5). Within the packaging systems day 3 had no significant difference $(p>0.05)$ whereas for day 5 there was significant difference between the packaging systems $(\mathrm{p}<0.05)$. Moreover, as can be seen from Table 5 there was not a clear reduction nor increase of the TA within the storage days meaning that not a significant amount of organic acid was used as a substrate for respiratory activity [28].

The $\mathrm{pH}$ values obtained in this study for cv. 'Flair' strawberries (Table 5) were a little below the range reported for cv. 'Elsanta' strawberries by Bovi, Caleb [10] and for cv. 'Sonata' strawberries by Caleb, Wegner, et al. (2016), which were in the range of 3.9 to 4.1 and 3.9 to 4.7, respectively. Similarly to TA, there was no significant difference between storage days for all packages except for unpacked and FP-30 samples, the magnitude of changes in $\mathrm{pH}$ were not higher than 0.3 in any of the samples. Within the packaging systems day 3 had no significant difference $(\mathrm{p}>0.05)$ whereas for day 5 there was significant difference between the packaging systems $(\mathrm{p}<0.05)$. This indicates that there was no significant changes in the acidity of the strawberry juice samples.

Also, for TSS values obtained in this study were above the reported by Caleb, Wegner [29], Bovi, Caleb [10], and Kallio, Hakala [27], which were in the range of 8.3-10.8, 4.0-5.2, and $5.35-10.96 \%$ respectively. This could suggest that the strawberries in this studies contained more sugar and were sweeter. There were no significant difference $(\mathrm{p}>0.05)$ within the storage days for control, FP-00, FP-20, FP-30, and FP-40. Within the packaging systems day 3 had no significant difference ( $p>0.05$ ) whereas for day 5 there was significant difference between the packaging systems $(\mathrm{p}<0.05)$. This could suggest that soluble sugars is converted and used-up for the fruit respiratory metabolism. Nevertheless, taking into consideration the 
duration of the study, the observed differences could also be due to natural variability of the strawberries such as the stage of ripeness [27].

\subsection{Visual and ortho-nasal quality evaluation}

All packages, except for unpacked and NatureFlex ${ }^{\mathrm{TM}}$, received scores above 3, indicating that the packaged strawberries were marketable at the end of storage day 5 (Fig 5). The extreme low scores for the unpacked can be associated with the excessive mass loss (33\%) as this led to extreme shriveling and wilting of the product, which in turn affect the texture, brilliance and decay directly. The sensorial analysis scores were in accordance with Fig 3, as packages covered with NatureFlex ${ }^{\mathrm{TM}}$ and Xtend films, and containing FruitPads had little or almost no visual condensation (scores between 5 and 4). This reduction was very important as it plays a very important role in consumer's choice.

Moreover, results obtained in this study are in accordance with Bovi, Caleb [10] as condensation was quantified as being close to zero (Fig. 4) but in the visual and ortho-nasal evaluation it was visible. As already discussed in the authors' work a possible reason for that is that the films absorbed water and formed droplets; being therefore visible to panelists but not detected in the quantification. Regarding quality attribute odour, the perceived odour for all packaged strawberry samples received an average score of 3, except for unpacked and NatureFlex ${ }^{\mathrm{TM}}$, indicating that no critical off-odour was recorded at the end of storage. This could be attributed to the fact that $\mathrm{O}_{2}$ did not decline below critical limit in any of the packages. Moreover, based on the results obtained by the Tukey's test, ortho-nasal evaluation showed that there were no significant differences only in decay between the packaged strawberry samples $(\mathrm{p}<0.05)$; all other parameters had significant differences.

\section{Conclusions}

A key finding of this study was that both enhanced permeable films and the FruitPads were able to reduce condensation as compared to the control sample under fluctuating temperature without affecting product quality. Furthermore, it was observed that both water elimination and water prevention strategies, namely FP-00, FP-20, FP-30 and Xtend ${ }^{\circledR}$, were the best in terms of reducing condensation while maintaining the mass loss without any significant difference. Furthermore, the water vapour flux needs of packaging materials under fluctuating temperature showed that the important parameter is not only ensuring that the package material water flux is as close as possible to the rate of the product transpiration losses but having a condensation control strategy. Therefore, in addition, packaging design 
should take into consideration a condensation control strategy that can eliminate, prevent or reduce excessive initial water released by product.

\section{Acknowledgement}

This work was supported by Conselho Nacional de Desenvolvimento Científico e Tecnológico (CNPq) through a PhD grant (201623/2015-3). The Georg Forster Postdoctoral Research Fellowship (HERMES) programme from the Alexander von Humboldt Foundation (Ref. ZAF-1160635-GFHERMES-P) is also appreciated. We also thank Dr. Filip Tintchev from McAirLaid's Vliesstoffe GmbH for providing us the FruitPads.

\section{References}

1. FAO, Global food losses and food waste - Extent, causes and prevention. Rome, 2011.

2. Mahajan, P.V., et al., Postharvest treatments of fresh produce. Philosophical Transactions of the Royal Society A, 2014. 372(2017): p. 1-16.

3. Lee, L., et al., A review on modified atmosphere packaging and preservation of fresh fruits and vegetables: Physiological basis and practical aspects-Part I. Packaging Technology and Science, 1995. 8(6): p. 315-331.

4. Kader, A.A., D. Zagory, and E.L. Kerbel, Modified atmosphere packaging of fruits and vegetables. Crit Rev Food Sci Nutr, 1989. 28(1): p. 1-30.

5. Kader, A.A., Biochemical and physiological basis for effects of controlled and modified atmospheres on fruits and vegetables. Food technology (USA), 1986.

6. Grossi-Bovi-Karatay, G., Innovations in modified atmosphere and humidity packaging applied to fresh produce: a case study on strawberries. 2019, Unpublished doctoral dissertation, Technical University Berlin, Berlin, Germany.

7. Rux, G., et al., Application of humidity-regulating tray for packaging of mushrooms. Postharvest Biology and Technology, 2015. 108: p. 102-110.

8. Rux, G., et al., Humidity-Regulating Trays: Moisture Absorption Kinetics and Applications for Fresh Produce Packaging. Food and Bioprocess Technology, 2016. 9(4): p. 709-716.

9. Jalali, A., et al., Application of humidity absorbing trays to fresh produce packaging: Mathematical modeling and experimental validation. Journal of Food Engineering, 2019. 244: p. 115-125.

10. Bovi, G.G., et al., Impact of modified atmosphere and humidity packaging on the quality, offodour development and volatiles of 'Elsanta' strawberries. Food Packaging and Shelf Life, 2018. 16: p. 204-210.

11. Volpe, S., et al., Condensation and moisture regulation in packaged fresh-cut iceberg lettuce. Journal of Food Engineering, 2018. 216(Supplement C): p. 132-137.

12. Madonna, M., et al., Understanding the physiological response of fresh-cut cauliflower for developing a suitable packaging system. Food Packaging and Shelf Life, 2018. 17: p. 179-186.

13. Belay, Z.A., et al., Design of Active Modified Atmosphere and Humidity Packaging (MAHP) for 'Wonderful' Pomegranate Arils. Food and Bioprocess Technology, 2018. 11(8): p. 1478-1494.

14. Caleb, O.J., et al., Integrated modified atmosphere and humidity package design for minimally processed Broccoli (Brassica oleracea L. var. italica). Postharvest Biology and Technology, 2016. 121: p. 87-100.

15. Rosenkranz, L., Effects of cellulose-based biodegradable film packaging on post-harvest physiological behaviour and quality attributes of tomatoes (Solanum lycopersicum L.), in Faculty of Life Sciences. 2016, Humboldt University of Berlin: Berlin. p. 1-47.

16. Bovi, G.G., et al., Moisture absorption kinetics of FruitPad for packaging of fresh strawberry. Journal of Food Engineering, 2018. 223: p. 248-254. 
17. Gaona-Forero, A., et al., Modeling and simulation of an active packaging system with moisture adsorption for fresh produce. Application in 'Hass' avocado. Food Packaging and Shelf Life, 2018. 17: p. 187-195.

18. Mahajan, P.V., et al., Development of a moisture absorber for packaging of fresh mushrooms (Agaricus bisporous). Postharvest Biology and Technology, 2008. 48(3): p. 408-414.

19. Bovi, G.G., et al., Transpiration and moisture evolution in packaged fresh horticultural produce and the role of integrated mathematical models: A review. Biosystems Engineering, 2016. 150: p. 24-39.

20. Jalali, A., et al., A comprehensive simulation program for modified atmosphere and humidity packaging (MAHP) of fresh fruits and vegetables. Journal of Food Engineering, 2017. 206: $p$. 88-97.

21. Bovi, G.G., et al., Measurement and modelling of transpiration losses in packaged and unpackaged strawberries. Biosystems Engineering, 2018. 174: p. 1-9.

22. Matar, C., et al., Predicting shelf life gain of fresh strawberries 'Charlotte $c v$ ' in modified atmosphere packaging. Postharvest Biology and Technology, 2018. 142: p. 28-38.

23. Yao, W., et al., Measuring the Deliquescence Point of Crystalline Sucrose as a Function of Temperature Using a New Automatic Isotherm Generator. International Journal of Food Properties, 2011. 14(4): p. 882-893.

24. Lipasek, R.A., et al., Effect of Temperature on the Deliquescence Properties of Food Ingredients and Blends. Journal of Agricultural and Food Chemistry, 2013. 61(38): p. 92419250.

25. Bovi, G.G. and P.V. Mahajan, Regulation of Humidity in Fresh Produce Packaging, in Reference Module in Food Science. 2017, Elsevier. p. 1-6.

26. Nunes, C.N. and J.P. Emond, Relationship between weight loss and visual quality of fruits and vegetables. Proceedings of the Florida State Horticultural Society, 2007. 120: p. 235-245.

27. Kallio, H., et al., Sugars and acids of strawberry varieties. European Food Research and Technology, 2000. 212(1): p. 81-85.

28. Belay, Z.A., et al., A simplex lattice design to optimise active modified atmosphere for storing pomegranate (cv. Wonderful) arils: Part II, determining optimum gas for maintaining quality attributes. Biosystems Engineering, 2019. 178: p. 322-335.

29. Caleb, O.J., et al., Hot water dipping: Impact on postharvest quality, individual sugars, and bioactive compounds during storage of 'Sonata' strawberry. Scientia Horticulturae, 2016. 210: p. 150-157. 


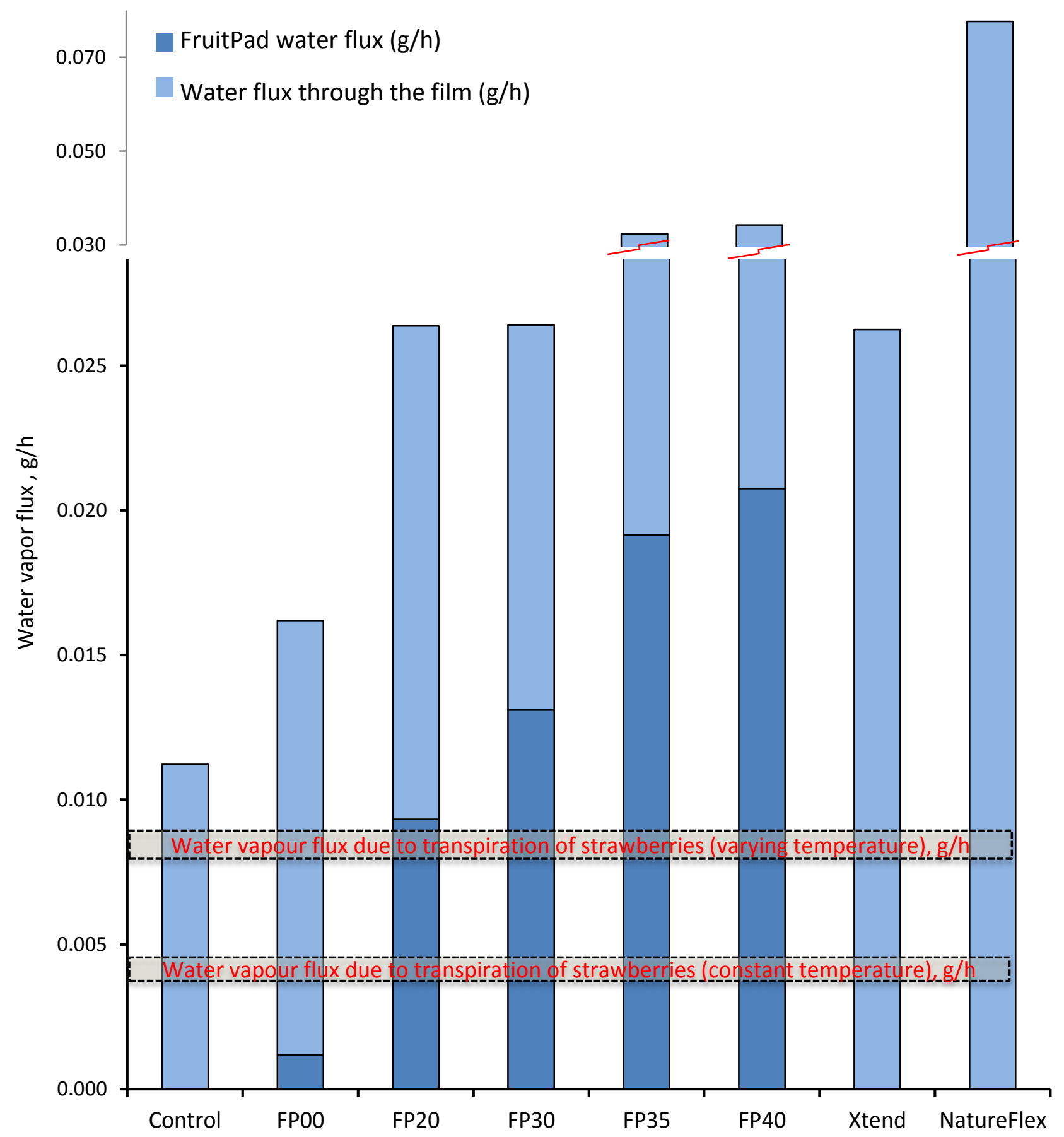

Fig 1. Water vapor flux due through the film and water flux of FruitPad absorption (vertical bars) and the rate of transpirational losses from packaged strawberries (horizontal bars) at constant $\left(12^{\circ} \mathrm{C}\right.$ ) and varying temperature $4^{\circ} \mathrm{C}$ to $20^{\circ} \mathrm{C}$ ). Standard deviation of $0.001 \mathrm{~g} \mathrm{~kg}^{-1} \mathrm{~h}^{-1}$ was used to calculate the range of transpirational loss. 


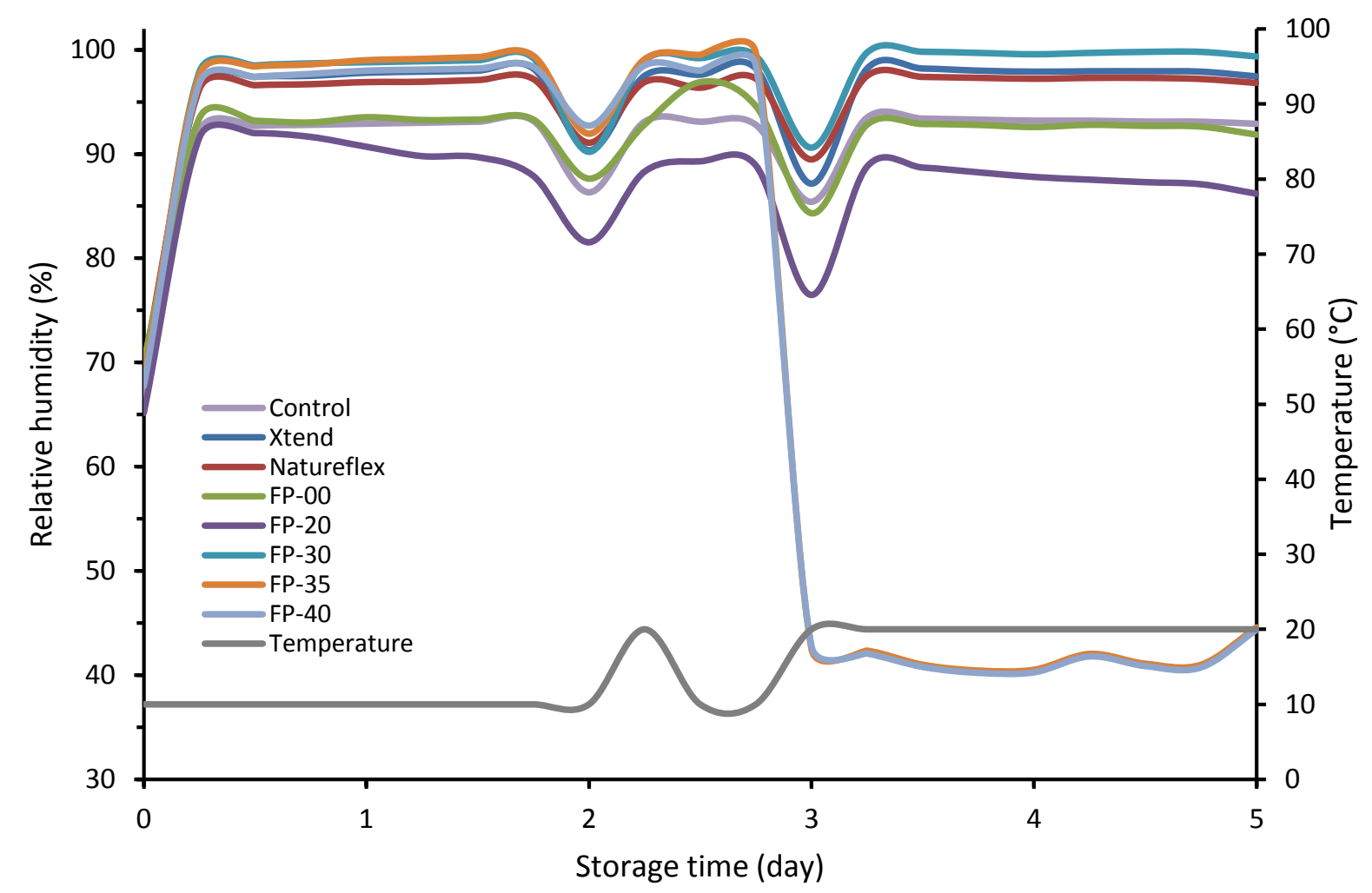

Fig 2. Impact of temperature fluctuation on relative humidity of package containing strawberries. 


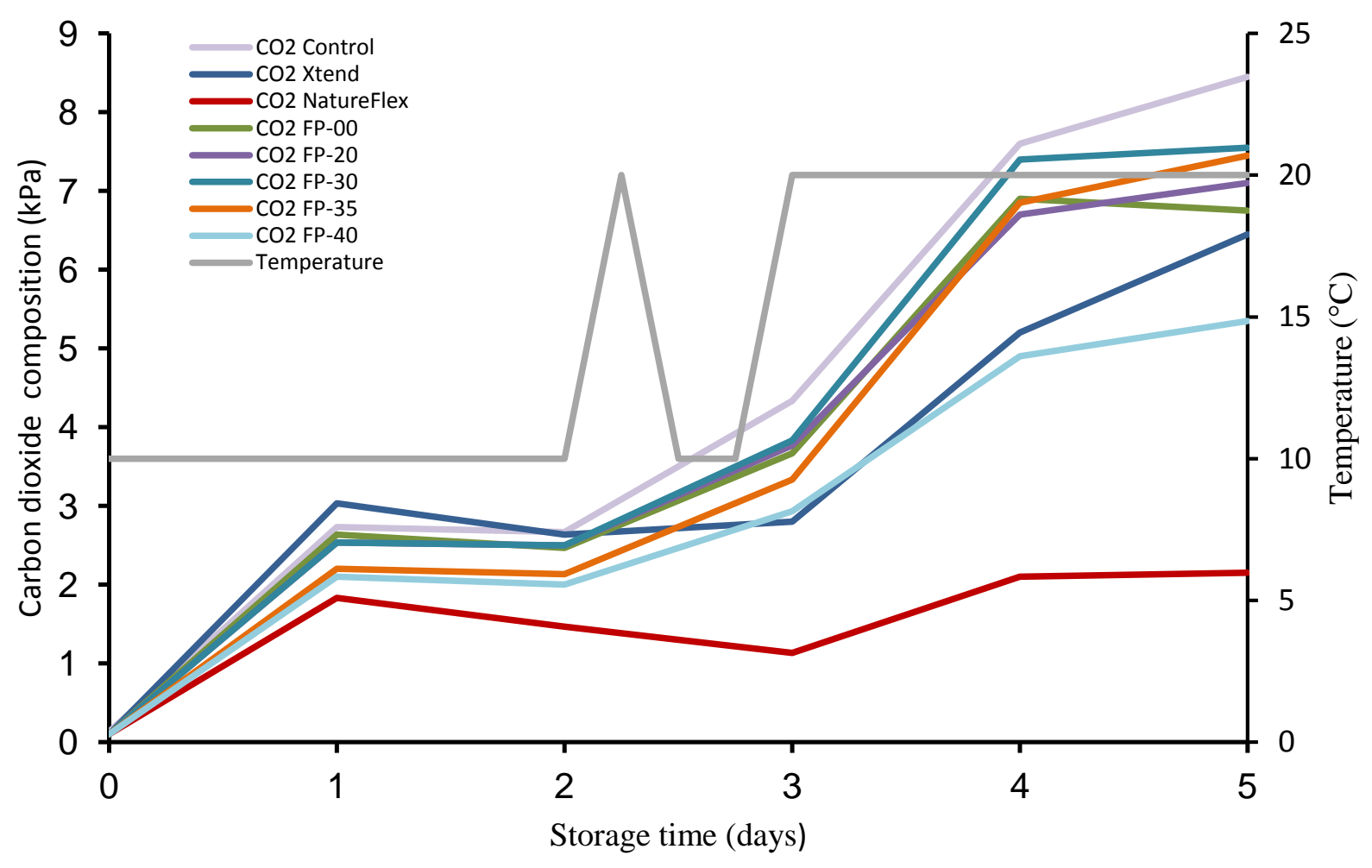

(b)

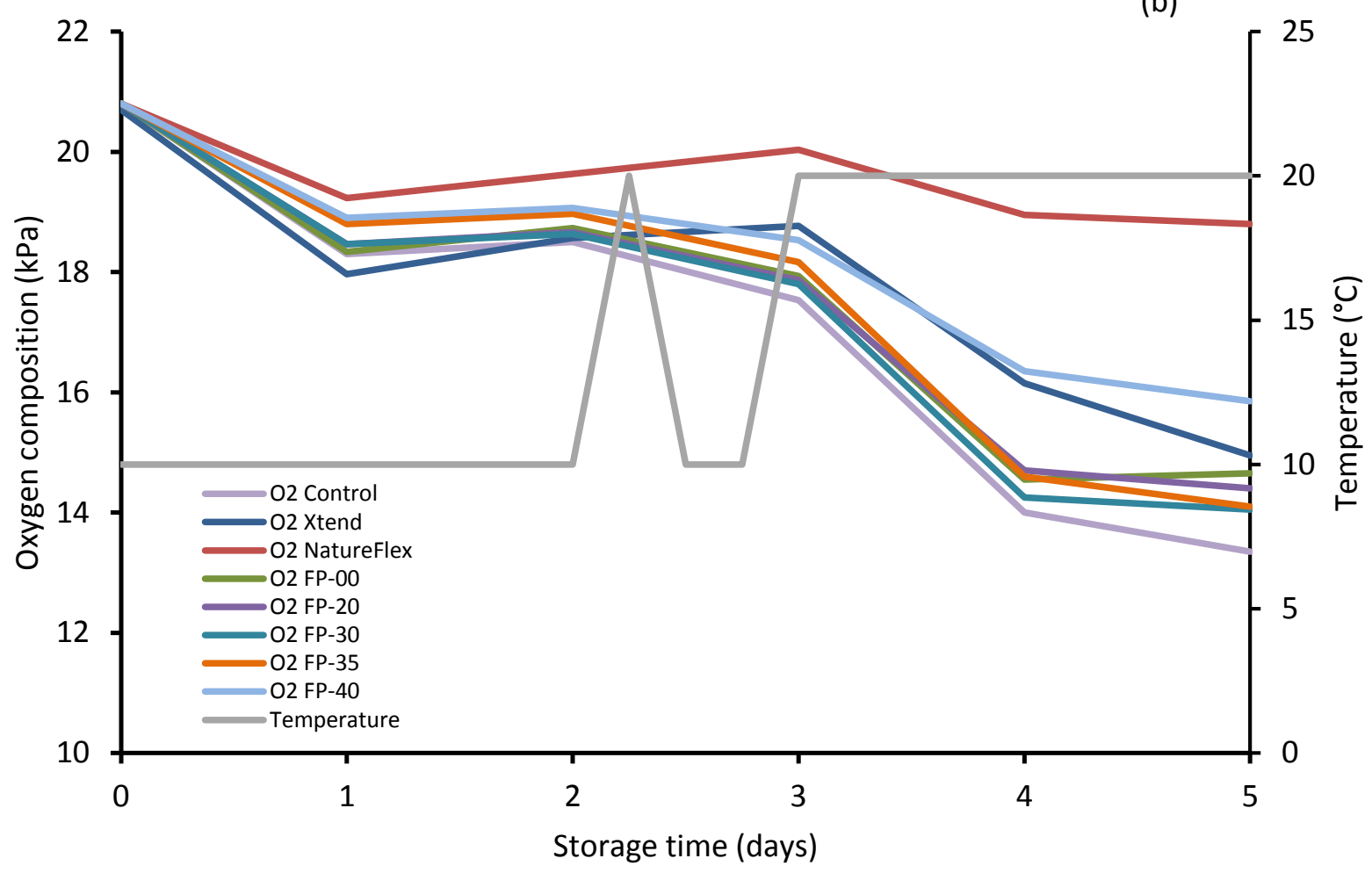

Fig 3. Changes in headspace gas composition of packaged strawberries stored under fluctuating temperature (a) carbon dioxide $(\mathrm{kPa})$ and $(\mathrm{b})$ oxygen $(\mathrm{kPa})$. 


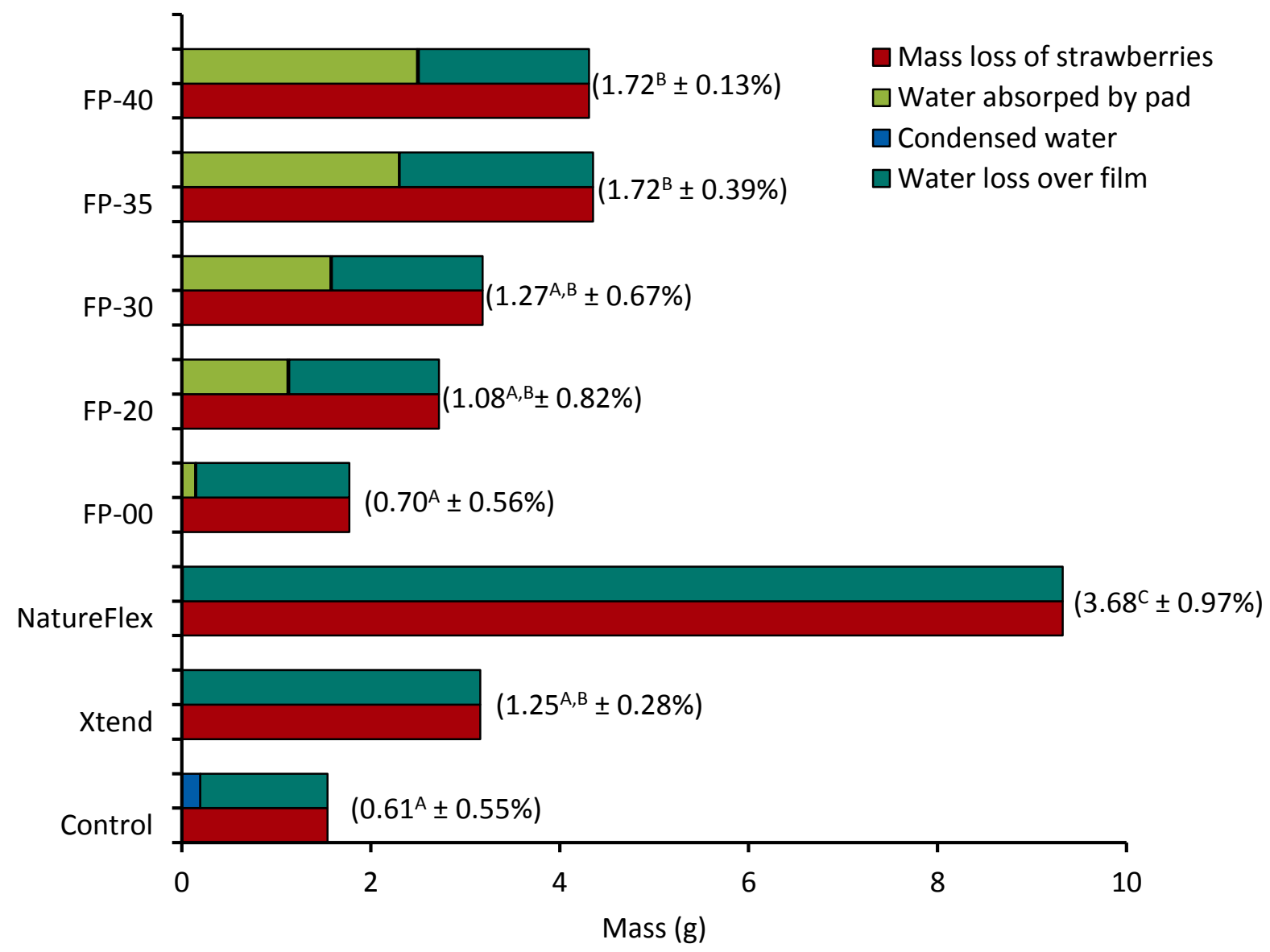

Fig 4. In-package moisture dynamics of strawberries packaged with different moisture control strategies stored under fluctuating temperature for $5 \mathrm{~d}$. The values in bracket represent the percentage mean values (mean value \pm standard derivation, $n=3$ ) for total strawberry mass loss. Different upper case superscript is significantly different based on Tukey test at $p \leq 0.05$. 


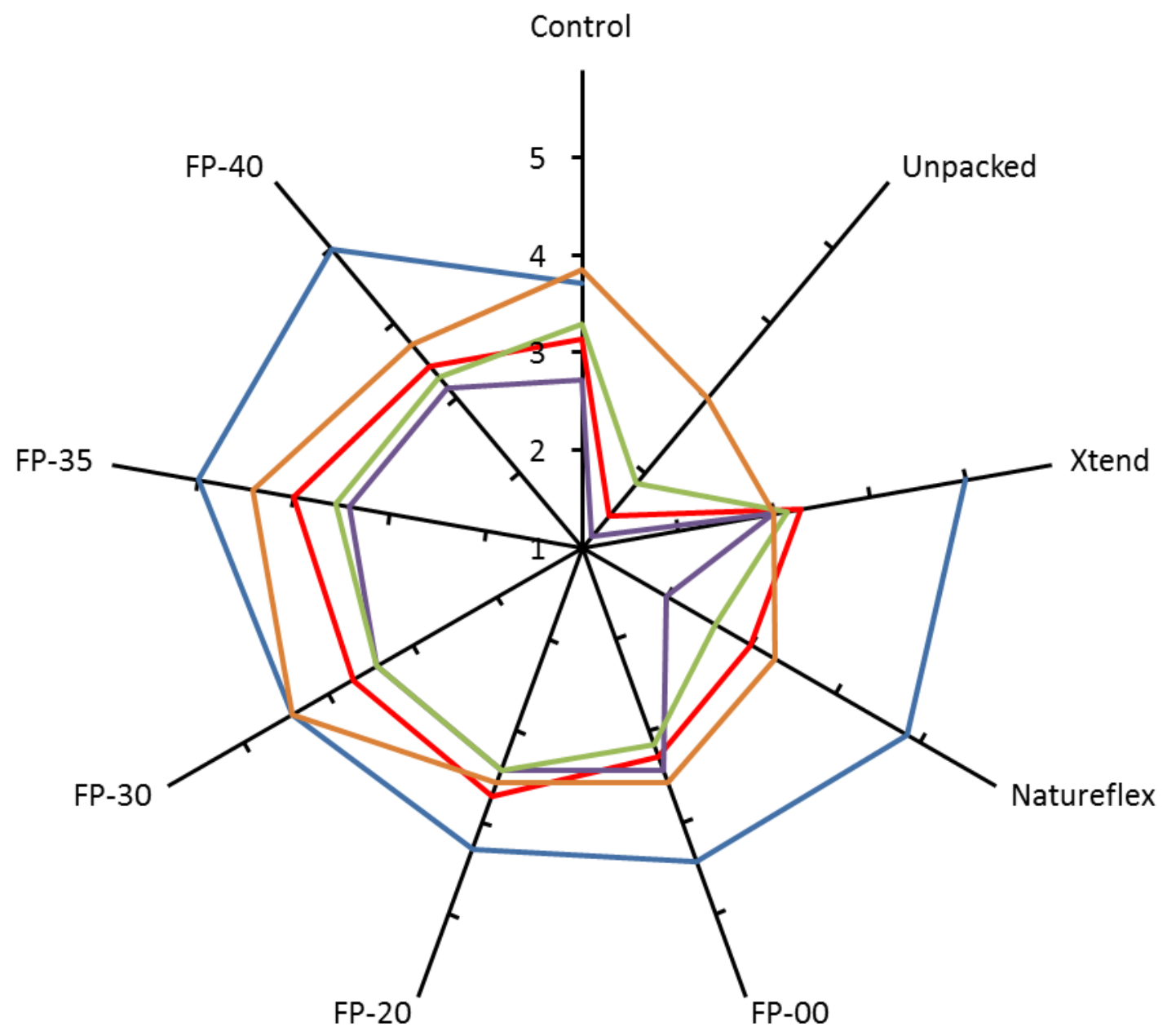

—In-package condensation - Texture Brilliance - Odour Decay

Fig 5. Changes in visual quality attributes of packaged strawberries and observed water vapour condensation after $5 \mathrm{~d}$ of storage under fluctuating temperature. 
Table 1. Practiced packaging and storage conditions of strawberries in the Potsdam area, Brandenburg, Germany

\begin{tabular}{|c|c|c|c|c|}
\hline \multirow{2}{*}{$\begin{array}{l}\text { Parameters } \\
\text { analysed }\end{array}$} & \multirow{2}{*}{$\begin{array}{c}\text { Supermarket } 1 \\
1\end{array}$} & \multicolumn{3}{|c|}{ Supermarket 2} \\
\hline & & 1 & 2 & $3^{*}$ \\
\hline $\mathrm{O}_{2}(\mathrm{kPa})$ & 17.1 & 20.7 & 20.7 & 20.7 \\
\hline $\mathrm{CO}_{2}(\mathrm{kPa})$ & 4.6 & 0.0 & 0.0 & 0.0 \\
\hline $\begin{array}{l}\text { Declared } \\
\text { mass }(\mathrm{g})\end{array}$ & 500 & 300 & 500 & 1000 \\
\hline $\begin{array}{l}\text { Strawberry } \\
\text { mass }(\mathrm{g})\end{array}$ & 499.9 & 308.7 & 507.0 & 1137.7 \\
\hline $\begin{array}{c}\text { Package } \\
\text { dimensions } \\
\text { (cm) }\end{array}$ & $19 \times 10.5 \times 5$ & $19 \times 11 \times 4$ & $18.5 \times 11.5 \times 8$ & $29.5 \times 19.5 \times 4.5$ \\
\hline $\begin{array}{l}\text { Type of } \\
\text { package }\end{array}$ & $\begin{array}{l}\text { Plastic clamshell } \\
\text { tray and film } \\
\text { cover }\end{array}$ & $\begin{array}{l}\text { Paper-based } \\
\text { tray and film } \\
\text { pouch }\end{array}$ & $\begin{array}{l}\text { Plastic clamshell } \\
\text { tray with plastic lid }\end{array}$ & $\begin{array}{l}\text { Wooden container } \\
\text { covered with paper } \\
\text { and film cover }\end{array}$ \\
\hline $\begin{array}{c}\text { \# of } \\
\text { perforations }\end{array}$ & 0 & $\begin{array}{c}18 \\
(\varnothing=7.5 \mathrm{~mm})\end{array}$ & $\begin{array}{c}12 \\
\left(\text { Area }=87.9 \mathrm{~mm}^{2}\right)\end{array}$ & $\begin{array}{c}18 \\
(\varnothing=8.33 \mathrm{~mm})\end{array}$ \\
\hline Condensation & yes & no & no & no \\
\hline Refrigeration & no & no & no & no \\
\hline
\end{tabular}


Table 2. Number of articles on MAP and MAHP over the last decade.

\begin{tabular}{|c|c|c|c|}
\hline \multirow[t]{2}{*}{ Keywords } & \multicolumn{2}{|c|}{ Number of articles } & \multirow{2}{*}{$\begin{array}{c}\text { Percentage change } \\
(\%)\end{array}$} \\
\hline & Before 2009 & After 2009 & \\
\hline MAP & 1652 & 2250 & 36.2 \\
\hline MAP AND fresh produce & 192 & 254 & 32.3 \\
\hline МАНР & 75 & 134 & 78.7 \\
\hline $\begin{array}{lll}\text { MAHP } & \text { AND } & \text { fresh } \\
\text { produce } & & \\
\end{array}$ & 15 & 32 & 113.3 \\
\hline
\end{tabular}


Table 3. Package design of the different packaging systems used in this study.

\begin{tabular}{|c|c|c|c|c|}
\hline Package type & $\begin{array}{l}\text { Lidding } \\
\text { film }\end{array}$ & $\begin{array}{l}\text { Film WVTR } \\
\qquad\left(\mathrm{g} \mathrm{m}^{2} \mathrm{~d}^{-1}\right)\end{array}$ & Film permeability rate to $\mathrm{O}_{2}$ & $\begin{array}{c}\% \text { of } \\
\text { fructose }\end{array}$ \\
\hline FP-00 & BOPP & & & 0 \\
\hline FP-20 & BOPP & & & 20 \\
\hline FP-30 & BOPP & 0.8 & $8.5 \times 10^{-12(* 1)}$ & 30 \\
\hline FP-35 & BOPP & & & 35 \\
\hline FP-40 & BOPP & & & 40 \\
\hline Control & BOPP & & & N/A \\
\hline NatureFlex $^{\mathrm{TM}}$ & $\mathrm{NF}$ & 42.79 & $6.1^{(* 2)}$ & N/A \\
\hline Xtend@ & $\mathrm{XT}$ & 19.34 & $24 \times 10^{-14}-48 \times 10^{-14(* 3)}$ & $\mathrm{N} / \mathrm{A}$ \\
\hline Unpacked & N/A & N/A & N/A & N/A \\
\hline
\end{tabular}

${ }^{(* 1)} \mathrm{mol} \mathrm{m}^{-2} \mathrm{~s}^{-1} \mathrm{~Pa}^{-1}\left(23{ }^{\circ} \mathrm{C}\right.$ and $\left.0 \% \mathrm{RH}\right),{ }^{(* 2)} \mathrm{mL} \mathrm{m}^{-2} \mathrm{~d}^{-1}\left(20{ }^{\circ} \mathrm{C}\right.$ and $\left.56 \% \mathrm{RH}\right),{ }^{(* 3)} \mathrm{mol} \mathrm{m}^{-2} \mathrm{~s}^{-1}$ $\mathrm{Pa}^{-1}$ (conditions not stated) 
1 Table 4. Quality scores and descriptors for strawberry.

\begin{tabular}{|c|c|c|c|c|c|}
\hline \multirow{2}{*}{ Descriptors } & \multicolumn{5}{|c|}{ Scores and description } \\
\hline & 1 & 2 & 3 & 4 & 5 \\
\hline $\begin{array}{l}\text { In-package } \\
\text { condensation }\end{array}$ & $\begin{array}{l}\text { Package surface is } \\
\text { extensively covered } \\
\text { with water vapour }\end{array}$ & $\begin{array}{l}\text { Package surface is } \\
\text { partially covered with } \\
\text { water vapour } \geq 50 \%\end{array}$ & $\begin{array}{l}\text { Package surface is partially } \\
\text { covered with water vapour } \\
\leq 50 \%\end{array}$ & $\begin{array}{l}\text { Package surface is } \\
\text { partially covered with } \\
\text { water vapour } \leq 25 \%\end{array}$ & $\begin{array}{l}\text { Package surface is } \\
\text { completely free of water } \\
\text { vapour condensation }\end{array}$ \\
\hline Texture & $\begin{array}{l}\text { Very poor (fruit are } \\
\text { extremely soft) }\end{array}$ & Poor (fruit are very soft) & $\begin{array}{l}\text { Fair (fruit exhibit minor } \\
\text { signs of softness) }\end{array}$ & Good (fruit are firm) & $\begin{array}{l}\text { Very good (fruit are } \\
\text { firm and turgid) }\end{array}$ \\
\hline Brilliance & Very dull looking & Dull looking & $\begin{array}{l}\text { Glossy looking (halfway } \\
\text { between shiny and dull) }\end{array}$ & Shiny looking & Very shiny looking \\
\hline Odour & Dislike very much & Dislike moderately & Neither like nor dislike & Like moderately & Like very much \\
\hline Decay & $\begin{array}{l}76-100 \% \\
\text { decay(extreme } \\
\text { decay/completely } \\
\text { rotten) }\end{array}$ & $\begin{array}{l}51-75 \% \text { decay (moderate } \\
\text { to severe decay) }\end{array}$ & $\begin{array}{l}26-50 \% \text { decay (spots with } \\
\text { decay) }\end{array}$ & $\begin{array}{l}1-25 \% \text { decay } \\
\text { (probable decay) }\end{array}$ & $0 \%$ decay (no decay) \\
\hline
\end{tabular}


Table 5. Effect of package design and storage duration on physicochemical properties of strawberries stored under fluctuating temperature for $5 \mathrm{~d}$.

\begin{tabular}{|c|c|c|c|c|c|c|c|c|c|c|}
\hline \multirow{2}{*}{ Parameter } & \multirow{2}{*}{ Storage $(d)$} & \multicolumn{9}{|c|}{ Package type } \\
\hline & & Control & Unpacked & Xtend & NatureFlex & FP-00 & FP-20 & FP-30 & FP-35 & $\mathrm{FP}-40$ \\
\hline \multirow[t]{3}{*}{ TSS (\%) } & 0 & $9.8 \pm 0.1^{\mathrm{A}}$ & $9.8 \pm 0.1^{A}$ & $9.8 \pm 0.1^{\mathrm{A}}$ & $9.8 \pm 0.1^{\mathrm{A}}$ & $9.8 \pm 0.1^{A}$ & $9.8 \pm 0.1^{A}$ & $9.8 \pm 0.1^{\mathrm{A}}$ & $9.8 \pm 0.1^{\mathrm{A}}$ & $9.8 \pm 0.1^{A}$ \\
\hline & 3 & $10.2 \pm 0.4^{\mathrm{A}, \mathrm{a}}$ & $11.5 \pm 1.1^{\mathrm{A}, \mathrm{B}, \mathrm{a}}$ & $12.4 \pm 1.7^{\mathrm{B}, \mathrm{a}}$ & $10.9 \pm 0.0^{\mathrm{A}, \mathrm{B}, \mathrm{a}}$ & $10.2 \pm 0.4^{\mathrm{A}, \mathrm{a}}$ & $10.3 \pm 1.5^{\mathrm{A}, \mathrm{a}}$ & $11.0 \pm 0.7^{A, a}$ & $10.3 \pm 0.6^{\mathrm{A}, \mathrm{a}}$ & $9.4 \pm 0.1^{\mathrm{A}, \mathrm{a}}$ \\
\hline & 5 & $11.1 \pm 1.0^{\mathrm{A}, \mathrm{a}}$ & $11.9 \pm 0.8^{\mathrm{B}, \mathrm{a}}$ & $11.5 \pm 0.3^{\mathrm{B}, \mathrm{a}, \mathrm{b}}$ & $11.6 \pm 0.9^{\mathrm{B}, \mathrm{a}, \mathrm{b}}$ & $10.8 \pm 1.1^{\mathrm{A}, \mathrm{a}, \mathrm{b}}$ & $10.2 \pm 0.9^{\mathrm{A}, \mathrm{a}}$ & $10.1 \pm 1.9^{\mathrm{A}, \mathrm{a}}$ & $8.7 \pm 0.5^{\mathrm{B}, \mathrm{a}}$ & $9.8 \pm 1.1^{\mathrm{A}, \mathrm{b}}$ \\
\hline \multirow[t]{3}{*}{ TA (citric acid) $\mathrm{g} \mathrm{L}^{-1}$} & 0 & $9.0 \pm 0.6^{\mathrm{A}}$ & $9.0 \pm 0.6^{\mathrm{A}}$ & $9.0 \pm 0.6^{A}$ & $9.0 \pm 0.6^{\mathrm{A}}$ & $9.0 \pm 0.6^{\mathrm{A}}$ & $9.0 \pm 0.6^{\mathrm{A}}$ & $9.0 \pm 0.6^{\mathrm{A}}$ & $9.0 \pm 0.6^{\mathrm{A}}$ & $9.0 \pm 0.6^{\mathrm{A}}$ \\
\hline & 3 & $9.8 \pm 0.8^{\mathrm{A}, \mathrm{a}}$ & $10.2 \pm 1.1^{\mathrm{A}, \mathrm{B}, \mathrm{a}}$ & $10.7 \pm 1.1^{\mathrm{A}, \mathrm{a}}$ & $10.5 \pm 1.4^{\mathrm{A}, \mathrm{a}}$ & $9.7 \pm 0.1^{\mathrm{A}, \mathrm{a}}$ & $10.3 \pm 1.5^{\mathrm{A}, \mathrm{a}}$ & $8.5 \pm 0.1^{\mathrm{A}, \mathrm{a}}$ & $9.8 \pm 0.1^{A, a}$ & $9.4 \pm 1.1^{\mathrm{A}, \mathrm{a}}$ \\
\hline & 5 & $9.8 \pm 0.4^{A, a, b}$ & $12.0 \pm 1.1^{\mathrm{B}, \mathrm{b}}$ & $9.9 \pm 0.8^{\mathrm{A}, \mathrm{a}, \mathrm{b}}$ & $11.0 \pm 1.2^{\mathrm{A}, \mathrm{a}, \mathrm{b}}$ & $9.5 \pm 0.6^{\mathrm{A}, \mathrm{a}, \mathrm{b}}$ & $9.1 \pm 0.2^{\mathrm{A}, \mathrm{a}}$ & $10.2 \pm 1.8^{\mathrm{A}, \mathrm{a}, \mathrm{b}}$ & $8.5 \pm 1.5^{\mathrm{A}, \mathrm{a}}$ & $9.2 \pm 1.9^{\mathrm{A}, \mathrm{a}}$ \\
\hline \multirow[t]{3}{*}{$\mathrm{pH}$} & 0 & $3.8 \pm 0.1^{A}$ & $3.8 \pm 0.1^{A}$ & $3.8 \pm 0.1^{A}$ & $3.8 \pm 0.1^{A}$ & $3.8 \pm 0.1^{A}$ & $3.8 \pm 0.1^{A}$ & $3.8 \pm 0.1^{A, B}$ & $3.8 \pm 0.1^{A}$ & $3.8 \pm 0.1^{A}$ \\
\hline & 3 & $3.6 \pm 0.2^{A, a}$ & $3.7 \pm 0.0^{\mathrm{A}, \mathrm{B}, \mathrm{a}}$ & $3.8 \pm 0.1^{\mathrm{A}, \mathrm{a}}$ & $3.7 \pm 0.1^{\mathrm{A}, \mathrm{a}}$ & $3.7 \pm 0.0^{\mathrm{A}, \mathrm{a}}$ & $3.7 \pm 0.0^{\mathrm{A}, \mathrm{a}}$ & $3.9 \pm 0.0^{\mathrm{A}, \mathrm{a}}$ & $3.8 \pm 0.0^{\mathrm{A}, \mathrm{a}}$ & $3.7 \pm 0.0^{A, a}$ \\
\hline & 5 & $3.7 \pm 0.1^{\mathrm{A}, \mathrm{a}, \mathrm{b}}$ & $3.7 \pm 0.0^{\mathrm{B}, \mathrm{a}, \mathrm{b}}$ & $3.6 \pm 0.1^{\mathrm{A}, \mathrm{a}}$ & $3.7 \pm 0.1^{A, a, b}$ & $3.7 \pm 0.1^{\mathrm{A}, \mathrm{a}, \mathrm{b}}$ & $3.7 \pm 0.0^{A, a, b}$ & $3.7 \pm 0.1^{\mathrm{B}, \mathrm{a}, \mathrm{b}}$ & $3.8 \pm 0.1^{A, b}$ & $3.8 \pm 0.1^{A, a, b}$ \\
\hline
\end{tabular}


